\title{
Predicting Conduction Heat Flux through Macrolayer in Nucleate Pool Boiling
}

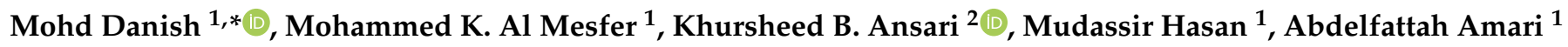 \\ and Babar Azeem ${ }^{3}$ \\ 1 Chemical Engineering Department, College of Engineering, King Khalid University, \\ Abha 61411, Saudi Arabia; almesfer@kku.edu.sa (M.K.A.M.); m-hasan@kku.edu.sa (M.H.); \\ aamari@kku.edu.sa (A.A.) \\ 2 Department of Chemical Engineering, Zakir Husain College of Engineering and Technology, \\ Aligarh Muslim University, Aligarh 202001, India; akabadruddin@myamu.ac.in \\ 3 Department of Chemical Engineering, The University of Faisalabad, Engineering Wing, \\ Faisalabad 38000, Pakistan; babar.azeem@tuf.edu.pk \\ * Correspondence: mdansh@kku.edu.sa; Tel.: +966-58-054-0101
}

Citation: Danish, M.; Al Mesfer, M.K.; Ansari, K.B.; Hasan, M.; Amari, A.; Azeem, B. Predicting Conduction Heat Flux through Macrolayer in Nucleate Pool Boiling. Energies 2021, 14, 3893. https://doi.org/10.3390/ en14133893

Received: 5 May 2021

Accepted: 23 June 2021

Published: 28 June 2021

Publisher's Note: MDPI stays neutral with regard to jurisdictional claims in published maps and institutional affiliations.

Copyright: (c) 2021 by the authors. Licensee MDPI, Basel, Switzerland. This article is an open access article distributed under the terms and conditions of the Creative Commons Attribution (CC BY) license (https:// creativecommons.org/licenses/by/ $4.0 /)$.

\begin{abstract}
In the current work, the heat flux in nucleate pool boiling has been predicted using the macrolayer and latent heat evaporation model. The wall superheat $(\Delta \mathrm{T})$ and macrolayer thickness $(\delta)$ are the parameters considered for predicting the heat flux. The influence of operating parameters on instantaneous conduction heat flux and average heat flux across the macrolayer are investigated. A comparison of the findings of current model with Bhat's decreasing macrolayer model revealed a close agreement under the nucleate pool boiling condition at high heat flux. It is suggested that conduction heat transfer strongly rely on macrolayer thickness and wall superheat. The wall superheat and macrolayer thickness is found to significantly contribute to conduction heat transfer. The predicted results closely agree with the findings of Bhat's decreasing macrolayer model for higher values of wall superheat signifying the nucleate boiling. The predicted results of the proposed model and Bhat's existing model are validated by the experimental data. The findings also endorse the claim that predominant mode of heat transfer from heater surface to boiling liquid is the conduction across the macrolayer at the significantly high heat flux region of nucleate boiling.
\end{abstract}

Keywords: heat flux; pool boiling; wall superheat; conduction

\section{Introduction}

Increased rate of heat transfer attributed to nucleate pool boiling is a vital regime of boiling. The nucleate boiling has been characterized by region of interference and isolated bubbles [1]. The pool boiling was investigated [2] with the help of illustrations of atmospheric pressure. Rough differentiation of various regions of nucleate pool boiling was hypothesized [3]. Previously, researchers [4] reported results comparable to those obtained by the investigators [2], and a marked decline in heat transfer coefficient was noticed in the second transition region. An investigation of saturated pool boiling was conducted pictorially and it was suggested that, as minimum, three and possibly four heat transfer regions be present. Katto and Yokoya [5] recommended a mechanism for nucleate boiling in which the heater surface is characterized by the existence of liquid film on it. In high heat flux region corresponding to nucleate pool boiling, the discrete bubbles leaving from the heated surface cannot escape into free space but amalgamate to form a large vapor mass due to high active site density. The vapor mass so formed still remains connected to the heating surface through a number of vapor column stems while a liquid layer is entrapped between the growing vapor mass and the heated surface. The liquid layer between the vapor mass and the heating surface is termed as "macrolayer." Whereas the microlayer is a liquid film that is much thinner, between an individual bubble and the heating surface 
during nucleate boiling at low heat flux. The evaporation of the liquid macrolayer has been hypothesized to be a controlling parameter in conduction heat transfer.

The study by Moissis and Berenson [6] specifically focused on the hydrodynamic transitions. Dhir [7] suggested that the prevailing mechanism of regime of pool boiling is characterized by high heat flux. Augmentation of the heat fluxes has been studied extensively by the investigators [8,9]. The bubble agitation model is signified by the bubbles' growth and release that cause the nearby liquid to undergo an exchange of heat $[10,11]$. Wall heat flux partitioning model based on bubble dynamics was studied for nucleate boiling [12] and a mechanistic model was suggested depending on combined heat transfer mechanism with relevant bubble dynamics. The results relying on the concept of vapor-liquid exchange model differ considerably from tangible conclusions $[13,14]$. A study employing the Lattice Boltzmann method $[15,16]$ contributed to enhanced heat transfer coefficient utilizing nanofluids. A computational fluid dynamics (CFD) method has been used to suggest the heat transfer coefficient corresponding to the nucleate regime of boiling [17]. A CFD study was conducted to analyze the influence of nanofluid on heat transfer coefficient for nucleate pool boiling under constant heat flux conditions [18]. It was suggested that the heat transfer coefficient increases with an increased amount of nanoparticles in the base fluid. Son and colleagues [19] studied the simulation of nucleate boiling and recommended that surface roughness contributed considerably to heat transfer. The effect of coating surface and gap size on heat transfer coefficient in pool boiling was investigated for deionized water at saturation temperature [20], and it was found that coated surface contributed to reduced heat transfer as compared with uncoated surface. $\mathrm{SiO}_{2}$ thin film nanocoated surface was used to study the significance of surface modification on heat transfer under nucleate pool boiling condition for saturated R-141b [21]. The obtained results were verified by correlations available in the literature. It was concluded that surface modifications lead to increased heat transfer. A horizontal heater was used to determine the nucleate pool boiling heat transfer coefficient for glycol-water alumina suspension [22], and a small heat transfer coefficient was observed for nano-suspension in comparison to that obtained for pure water. Ambient conditions were controlled to numerically analyze the nucleate boiling of saturated water [23]. A macroscopic model that considers free board region was developed for nucleate pool boiling in openFOAM and verified using experimental data [24]. It was suggested that turbulence dispersion force contributes to aeration in the bulk liquid. The macrolayer model [25] was utilized for studying the nucleate heat exchange employing the numerical simulation. The volume-offluid (VOF) concept has been employed to analyze the nucleate boiling phenomenon [26]. A CFD model based on the microlayer has been developed to simulate boiling regime of industrial significance [27].

A CFD study of nucleate boiling using cryogenic fluid has been performed [28], and the findings agree well with the obtained data. A study devoted to numerical analysis using a thin substrate of nucleate heat transfer has been carried out [29]. An enhanced VOF method [30] was employed to study the detachment characteristics of isolated bubbles. Heat exchange across the boundary between the vapor, liquid, and solid phases has been predicted [31]. Modeling and numerical study was performed to predict the role of the microlayer in heat transfer using a water-ethanol system [32]. The entire range of nucleate boiling was studied using developed comprehensive relationships [33]. The heat transfer coefficient has been predicted at different concentrations using $\mathrm{TiO}_{2}$-water nanofluids to present a new model [34]. The fractal distribution of nucleation sites has been studied using a model developed by Chu and colleagues [35]. A static and dynamic model [36] characterizing the growth of vapor bubbles on heated walls has been studied extensively. The vapor-liquid boundary's hydrodynamic response has been reported by developed model [37].

An unsteady-state model for energy exchange across the macrolayer has been presented [38,39]. An alternate critical heat flux theory based on the significance of the macrolayer was proposed by Haramura and Katto [40] and Pan et al. [41]. These proposed 
models do not alter the fundamental elements of Zuber's model [42]. Dhir and Liaw [43] presented their conclusions in a time-averaged model. Bhat et al. [44,45] developed an analytical heat transfer model corresponding to a nucleate regime of boiling, supposing fixed macrolayer thickness. The Bhat et al. study [45] assumed a linear temperature profile in the liquid macrolayer for the total cycle period of vapor mass initiation-growth departure, and the governing equations (Equations (1)-(4)) for macrolayer thickness, conduction heat flux, average conduction heat flux, and dimensional temperature have been reproduced below.

An expression for instantaneous value macrolayer thickness is represented by:

$$
y=\delta_{o}-\frac{q_{w} t}{\rho_{l} h_{\mathrm{fg}}}
$$

At a temperature difference of $\Delta \mathrm{T}$, conduction heat flux equation can be written as:

$$
q_{c}=k \Delta T \rho_{l} h_{f g}\left[\frac{1}{\rho_{l} h_{f g} \delta_{o}-q_{w} t}\right]
$$

The conduction heat flux in terms of average value is obtained as:

$$
q_{a v g}=\rho_{l} h_{f g} \frac{k \Delta \mathrm{TF}}{q_{w}} \ln \left(\frac{\delta_{o}}{\delta_{o}-\left(q_{w} / \rho_{l} h_{f g} F\right)}\right)
$$

Assuming the linear temperature profile in macrolayer as:

$$
\theta=\frac{T-T_{s}}{T_{w}-T_{s}}=\left(\frac{\delta_{0}}{\delta_{0}-\left(q_{w} t / \rho_{l} h_{f g}\right)}\right)\left(1-\frac{y}{\delta_{0}}\right)
$$

The heat exchange across the macrolayer at a constant heat input was investigated by Prasad [46]. Jairajpuri and Saini [47] developed an unsteady-state heat exchange model of diminishing macrolayer thickness. An analytical solution using Laplace transformation of the heat exchange model based on macrolayer has been presented [48]. An unsteady-state model considering heat exchange in the heater wall and macrolayer was developed by Prasad and colleagues [49]. A detailed investigation was carried out, taking into consideration the heat exchange and bubble dynamics [50]. The importance of the hydrophobic/hydrophilic surface was examined with mesoscale simulated boiling curves [51]. A simulation study on a single site, using a large, microscopic contact angle, a moderate Jakob number, and a high-density ratio between phases was carried out [52]. Nucleate pool boiling for water and water-silica nanofluid was simulated [53], applying the Eulerian multiphase approach, and simulated findings were compared with experimental data to substantiate the proposed approach.

The effect of microgravity on heat transfer under the pool boiling condition was investigated by mesoscale simulations [54]. CHF improvement was obtained with increased concentration of GONs using aqueous nanofluids under unsteady-state nucleate boiling [55]. Water-based graphene oxide colloidal suspensions were chosen using silicon dioxide plate surface to augment the critical heat flux [56]. Investigators [57] have reported an augmentation of $80 \%$ in the heat transfer coefficient during a heat transfer study of water on $\mathrm{SiO}_{2}$ nanostructure surface. An extensive review on $\mathrm{CHF}$ has been conducted with special emphasis on mechanism, models, and correlations [58]. Also proposed was a new correlation to predict the heat transfer coefficient considering the influence of surface/liquid combination [59].

An algorithm employing the VOF aspect was evolved [60] to microlayer evaporation and single bubble behavior during nucleate boiling. An investigation [61] of heat exchange in nucleate regime of pool boiling using R124a/R245f azeotropic mixture was carried out. An extensive review on the various surface modification techniques has been proposed 
to augment the critical heat flux in saturated pool boiling [62]. A study to develop a CHF model was conducted considering micro-scale surface roughness [63].

The purpose of the current study is to predict the energy exchange utilizing the macrolayer model. The outcome of macrolayer thickness and wall superheat on heat flux and average heat flux is investigated. The relative contribution of wall superheat and macrolayer thickness to the conduction heat flux is analyzed. The predicted results are compared with the decreasing macrolayer model developed by Bhat et al. [45] and predicted results are validated with the available literature data.

\section{Current Model and Analytical Solution}

The developed mathematical model (Equation (5)) and detailed analytical solution presented elsewhere [48] for heat transfer through the macrolayer and the corresponding equations (Equations (6)-(9)) obtained through the analytical solution of the developed model using appropriate boundary and initial conditions for conduction heat flux, average conduction heat flux, and temperature profile are presented as follows.

$$
\alpha \frac{\partial^{2} T}{\partial y^{2}}-V \frac{\partial T}{\partial y}=\frac{\partial T}{\partial t}
$$

where $V$ denotes liquid-vapor interface velocity and is characterized by rate of evaporation of macrolayer at liquid-vapor interface.

The initial and boundary conditions on $T(y, t)$ are:

$$
\begin{array}{llll}
\text { I.C.: } & T(y, 0)=T_{w} ; & 0 \leq y \leq \delta & T_{w} \text { : wall temperature } \\
\text { B.C.: } & T(0, t)=T_{w} ; & t>0 & T_{s} \text { : surface temperature } \\
& T(\delta, t)=T s ; & t>0 . &
\end{array}
$$

The conduction heat flux $q_{c}$ at $y=\delta$ is given as:

$$
q_{c}=k \Delta T\left[\frac{v}{\alpha\left(1-\exp \left(\frac{-v \delta}{\alpha}\right)\right)}+\sum_{n=1}^{\infty} \frac{2 n^{2} \pi^{2}}{\delta\left(\frac{v^{2} \delta^{2}}{4 \alpha^{2}}+n^{2} \pi^{2}\right) \exp \left(\frac{v^{2}}{4 \alpha}+\frac{n^{2} \pi^{2} \alpha}{\delta^{2}}\right) t}\right]
$$

The heat flux averaged $q_{\text {avg }}$ over time interval $t_{c}$ is defined as:

$$
\begin{gathered}
q_{a v g}=\int_{0}^{t_{c}} q_{c} d t . \\
q_{a v g}=\frac{k \Delta T}{t_{c}}\left\{\frac{v t_{c}}{\alpha\left(1-\exp \left(\frac{-v s}{\alpha}\right)\right)}-\sum_{n=1}^{\infty} \frac{2 n^{2} \pi^{2} \alpha\left\{\exp -\left(\frac{v^{2}}{4 \alpha}+\frac{n^{2} \pi^{2} \alpha}{\delta^{2}}\right) t c-1\right\}}{\delta^{3}\left(\frac{v^{2}}{4 \alpha}+\frac{n^{2} \pi^{2} \alpha}{\delta^{2}}\right)^{2}}\right\}
\end{gathered}
$$

The equation for temperature profile in dimensionless form in macrolayer is expressed as:

$$
\theta(y, t)=e^{\frac{v}{2 \alpha}(y-\delta)}\left[\frac{\sin h \frac{v}{2 \alpha} y}{\sin h \frac{v}{2 \alpha} \delta}+\sum_{n=1}^{\infty} \frac{2 n \pi(-1)^{n} \sin n \pi y / \delta}{\left(\frac{v^{2}}{4 \alpha}+\frac{n^{2} \pi^{2} \alpha}{\delta^{2}}\right) \exp \left(\frac{v^{2}}{4 \alpha}+\frac{n^{2} \pi^{2} \alpha}{\delta^{2}}\right) t}\right]
$$

where dimensionless temperature, $\theta=\frac{T_{W}-T}{T_{W}-T_{S}}$.

\section{Results and Discussion}

\subsection{Instantaneous Heat Fluxes}

The dependence of average flux predicted by Bhat's model and the current model $(t=1 \mathrm{~ms})$ is shown in Figure 1. The data were obtained for a total cycle period of $40 \mathrm{~ms}$ with three macrolayer thicknesses of $50 \mu \mathrm{m}, 75 \mu \mathrm{m}$, and $200 \mu \mathrm{m}$ for Bhat's existing model. The macrolayer thicknesses of $50 \mu \mathrm{m}, 150 \mu \mathrm{m}$, and $200 \mu \mathrm{m}$ with $t=40 \mathrm{~ms}$ were used to predict the heat fluxes using the current model. It is found that the average heat flux increases with increased wall superheat and a thinner macrolayer contributes significantly to heat 
exchange. Bhat's model predicted a highest heat flux of $1.2569 \mathrm{MW} / \mathrm{m}^{2}$ and our model predicted a heat flux of $1.5165 \mathrm{MW} / \mathrm{m}^{2}$ at the same wall superheat of $50 \mathrm{~K}$, corresponding to a macrolayer thickness of $50 \mu \mathrm{m}$, respectively.

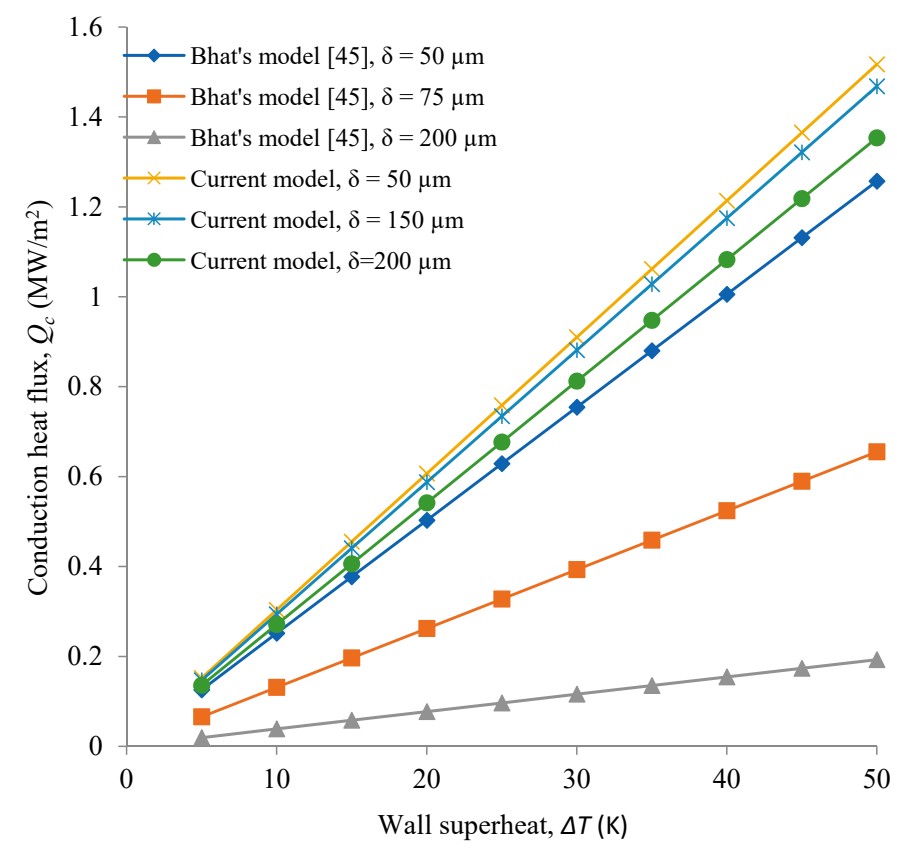

Figure 1. Dependence of heat flux on wall superheat using current model and Bhat's model.

The instantaneous conduction heat fluxes predicted by the current model are higher than those obtained using the decreasing macrolayer model of Bhat [45] at all the selected constant values of the macrolayer thicknesses, indicating the significance of proposed model. The deviations between the fluxes predicted by both models increased with increased macrolayer thickness. The current model and Bhat's model predicted maximum heat fluxes of $1.3535 \mathrm{MW} / \mathrm{m}^{2}$ and $0.1929 \mathrm{MW} / \mathrm{m}^{2}$, respectively, at a macrolayer thickness of $200 \mu \mathrm{m}$. From the analysis of curves, it is suggested that energy exchange rate strongly depends on $\Delta T$. A thicker macrolayer transports less heat energy at the equivalent magnitude of wall superheat. The accuracy measurement is determined in terms of coefficient of determination $\left(R^{2}\right)$ and mean error $(\sigma)$ for both (current and existing) models' data [45]. An $R^{2}=0.899$ is determined with reference to Figure 1 for dependence of instantaneous conduction heat flux on wall superheat for the current model and Bhat's model for macrolayer thickness, $\delta=50 \mu \mathrm{m}$. Also, the mean error or standard deviation $(\sigma)$ is estimated to be $\pm 0.078 \mathrm{MW} / \mathrm{m}^{2}$. The lower value of standard deviation validates good agreement between the current model and Bhat's model based on the macrolayer.

Figure 2 shows the comparative heat fluxes with macrolayer thickness estimated using the current model $(t=10 \mathrm{~ms})$ and Bhat's model $(t=30 \mathrm{~ms})$ under constant conditions of wall superheat. The data were obtained for wall superheats of $40 \mathrm{~K}, 30 \mathrm{~K}$, and $20 \mathrm{~K}$ for both the examined models. The conduction heat fluxes predicted by these models decrease significantly with increased macrolayer thicknesses from $30 \mu \mathrm{m}$ to $200 \mu \mathrm{m}$. The current model predicted a heat flux of $1.6339 \mathrm{MW} / \mathrm{m}^{2}$ at wall superheat of $40 \mathrm{~K}$ at a departure time of $10 \mathrm{~ms}$, whereas Bhat's model predicted the highest energy flux of $2.1199 \mathrm{MW} / \mathrm{m}^{2}$ under the same condition of wall superheat. Under a constant condition of wall superheat $(\Delta T=30 \mathrm{~K})$, the current model and Bhat's model predicted instantaneous maximum heat fluxes of $1.2254 \mathrm{MW} / \mathrm{m}^{2}$ and $1.5899 \mathrm{MW} / \mathrm{m}^{2}$, respectively. It was noticed that the impact of macrolayer thickness on instantaneous conduction fluxes is less prominent at a higher thickness, for example, at about $200 \mu \mathrm{m}$. 


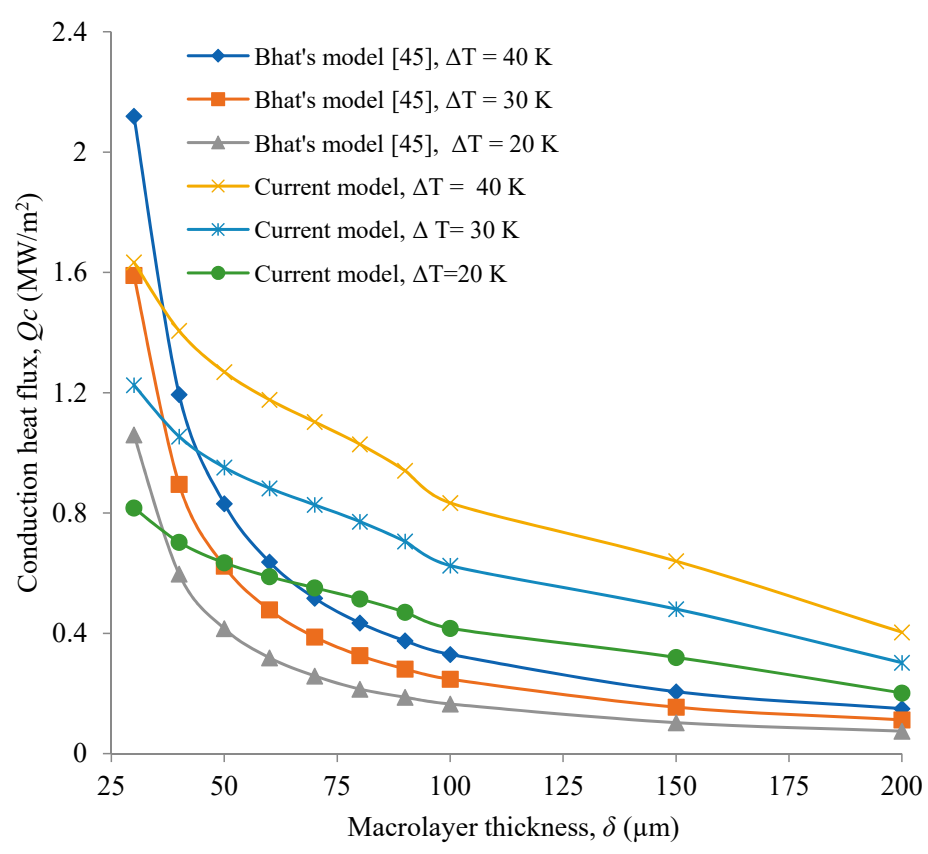

Figure 2. Prediction of heat fluxes with macrolayer thickness using current model.

\subsection{Average Conduction Heat Fluxes}

The dependence of average conduction energy flux obtained for the current model $\left(t_{c}=40 \mathrm{~ms}\right)$ and Bhat's decreasing macrolayer model $(1 / \mathrm{F}=40 \mathrm{~ms})$ is shown in Figure 3. The average conduction heat flux is defined at the liquid-vapor interface. The macrolayer thicknesses of $50 \mu \mathrm{m}, 150 \mu \mathrm{m}$, and $200 \mu \mathrm{m}$ are chosen to predict the average conduction heat fluxes using the current model, whereas macrolayer thicknesses of $50 \mu \mathrm{m}, 75 \mu \mathrm{m}$, and $200 \mu \mathrm{m}$ were chosen to predict the heat fluxes utilizing Bhat's model. The average flux is found to increase with increased wall superheat, and a thinner macrolayer contributes to significant heat exchange across the macrolayer.

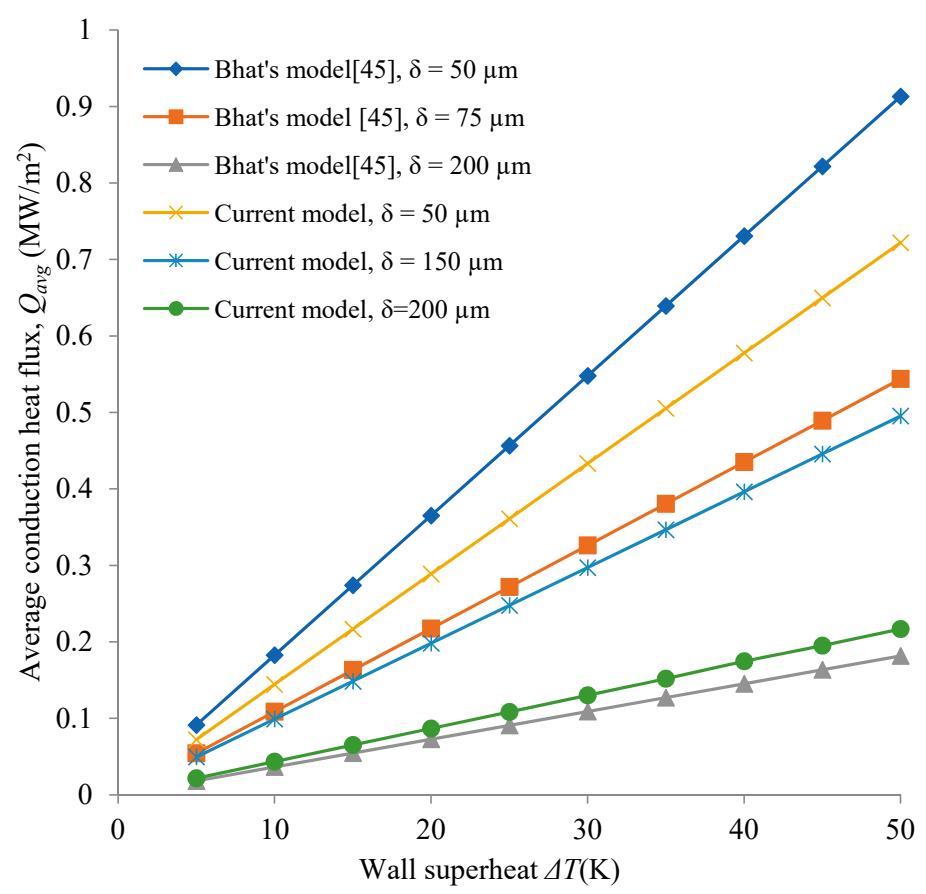

Figure 3. Dependence of average heat fluxes on wall superheat $\left(t_{c}=40 \mathrm{~ms}, 1 / \mathrm{F}=40 \mathrm{~ms}\right)$. 
The consequence of macrolayer thickness on average conduction heat flux is pronounced significantly with increased thickness, say, at $200 \mu \mathrm{m}$. The average heat flux declines from $0.4952 \mathrm{MW} / \mathrm{m}^{2}$ to $0.2168 \mathrm{MW} / \mathrm{m}^{2}$ with increased macrolayer thickness from $150 \mu \mathrm{m}$ to $200 \mu \mathrm{m}$ under a constant condition of wall superheat $(\Delta T=50 \mathrm{~K})$ for the current model. Bhat's model and the current model predicted a maximum average heat flux of $0.9131 \mathrm{MW} / \mathrm{m}^{2}$ and $0.7219 \mathrm{MW} / \mathrm{m}^{2}$ at a wall superheat of $50 \mathrm{~K}$ under a constant macrolayer thickness of $50 \mu \mathrm{m}$. The current model predicts better results for a thicker macrolayer of $200 \mu \mathrm{m}$ as compared with that predicted by Bhat's model. The average fluxes of $0.1745 \mathrm{MW} / \mathrm{m}^{2}$ and $0.1452 \mathrm{MW} / \mathrm{m}^{2}$ are obtained for the current model and Bhat's model, respectively, under a constant condition of wall superheat $(\Delta T=40 \mathrm{~K})$ at an increased macrolayer thickness of $200 \mu \mathrm{m}$. From the analysis of curves, it is observed that average energy rate relies intensely on $\Delta T$. For the same cycle period and same superheat, a thinner macrolayer contributes to higher heat energy irrespective of the chosen model.

The comparative analysis of the average conduction heat fluxes obtained using the current model and Bhat's model [45] is presented in Figure 4. Bhat's model predicted the heat fluxes for macrolayer thicknesses of $50 \mu \mathrm{m}, 75 \mu \mathrm{m}$, and $200 \mu \mathrm{m}$ over a cycle period $(1 / \mathrm{F})$ of $50 \mathrm{~ms}$. A total cycle time $\left(t_{c}\right)$ of $60 \mathrm{~ms}$ was used to predict the heat fluxes with macrolayer thicknesses of $50 \mu \mathrm{m}, 150 \mu \mathrm{m}$, and $200 \mu \mathrm{m}$ for the current model. In all cases of heat flux predicted by Bhat's model and the present model, the average conduction heat flux depends intensively on $\Delta \mathrm{T}$. Considerable deviations are observed between the heat fluxes obtained for the present model and Bhat's decreasing macrolayer model. The deviations are more pronounced at a larger value of wall superheat. The present model predicts a maximum average flux of $0.7212 \mathrm{MW} / \mathrm{m}^{2}$ as compared with an average flux of $1.0125 \mathrm{MW} / \mathrm{m}^{2}$ obtained for Bhat's model at a $\Delta \mathrm{T}$ value of $50 \mathrm{~K}$ and a macrolayer thickness of $50 \mu \mathrm{m}$. The results predicted by both models are nearly the same for a macrolayer thickness of $200 \mu \mathrm{m}$.

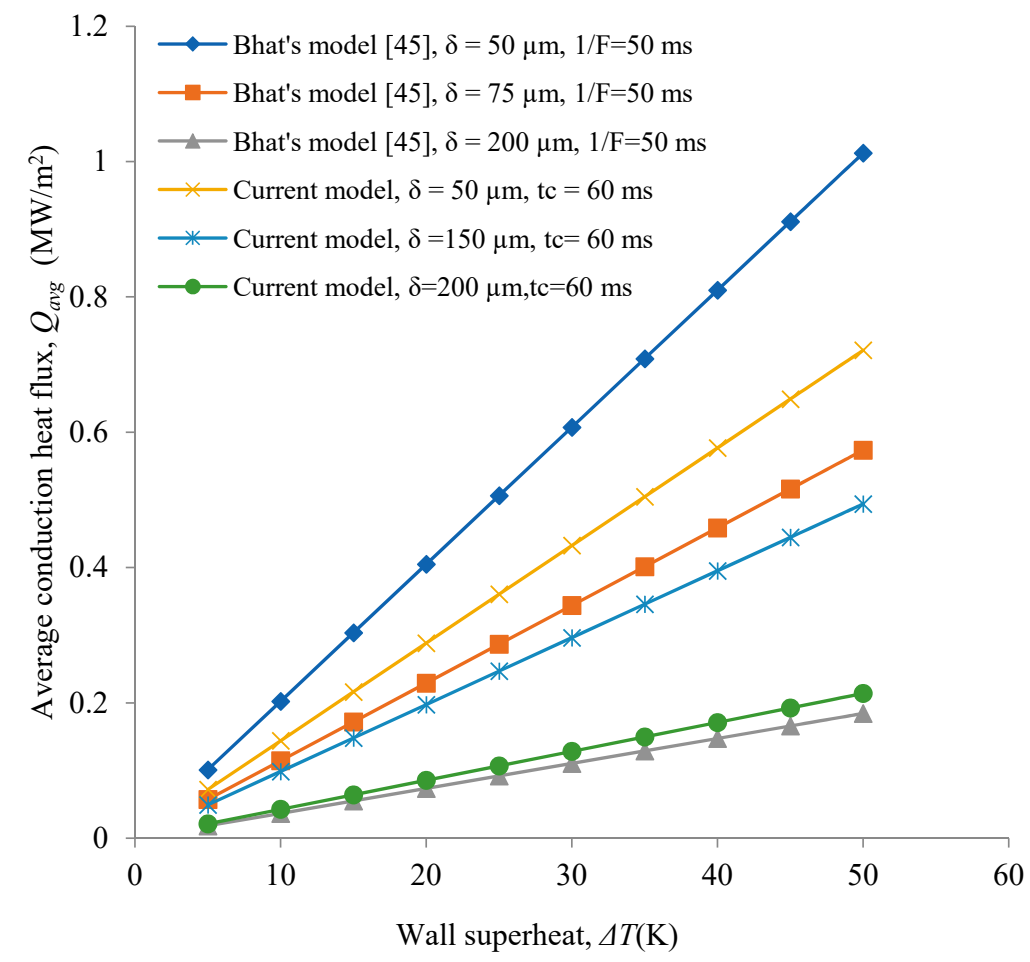

Figure 4. Prediction of average conduction heat fluxes with wall superheat ( $t_{c}=60 \mathrm{~ms}, 1 / \mathrm{F}=50 \mathrm{~ms}$ ).

The dependence of average conduction heat fluxes for the current model $\left(t_{c}=40 \mathrm{~ms}\right)$ and Bhat's model $(1 / \mathrm{F}=40 \mathrm{~ms})$ on macrolayer thickness under constant conditions of wall superheats of $40 \mathrm{~K}, 30 \mathrm{~K}$, and $20 \mathrm{~K}$ is presented in Figure 5. It is observed that energy exchange rate varies significantly with macrolayer thickness. Bhat's model and the current 
model predict maximum heat fluxes of $1.7118 \mathrm{MW} / \mathrm{m}^{2}$ and $0.9415 \mathrm{MW} / \mathrm{m}^{2}$, respectively, at a $\delta$ value of $30 \mu \mathrm{m}$ under constant conditions of wall superheat, $\sim 40 \mathrm{~K}$. The predicted $Q_{\text {avg }}$ for the current model declines from $0.7061 \mathrm{MW} / \mathrm{m}^{2}$ to $0.1301 \mathrm{MW} / \mathrm{m}^{2}$ with increased macrolayer thickness from $30 \mu \mathrm{m}$ to $200 \mu \mathrm{m}$ at a $\Delta T$ equivalent to $30 \mathrm{~K}$, corresponding to a total time of $40 \mathrm{~ms}$. It is also observed that, under the constant operating conditions of macrolayer thickness and total cycle time, the predicted average heat flux was enhanced with increased wall superheat. Heat flux predicted by the current model enhanced from $0.3569 \mathrm{MW} / \mathrm{m}^{2}$ to $0.7138 \mathrm{MW} / \mathrm{m}^{2}$ with increased wall superheat from $20 \mathrm{~K}$ to $40 \mathrm{~K}$ for macrolayer thickness of $40 \mu \mathrm{m}$. It is clear from these curves that the predicted average heat fluxes vary significantly with macrolayer $(\delta)$. The findings show that the average energy exchange rate declines with augmented macrolayer thickness, indicating that an insubstantial macrolayer contributes to significantly higher flux.

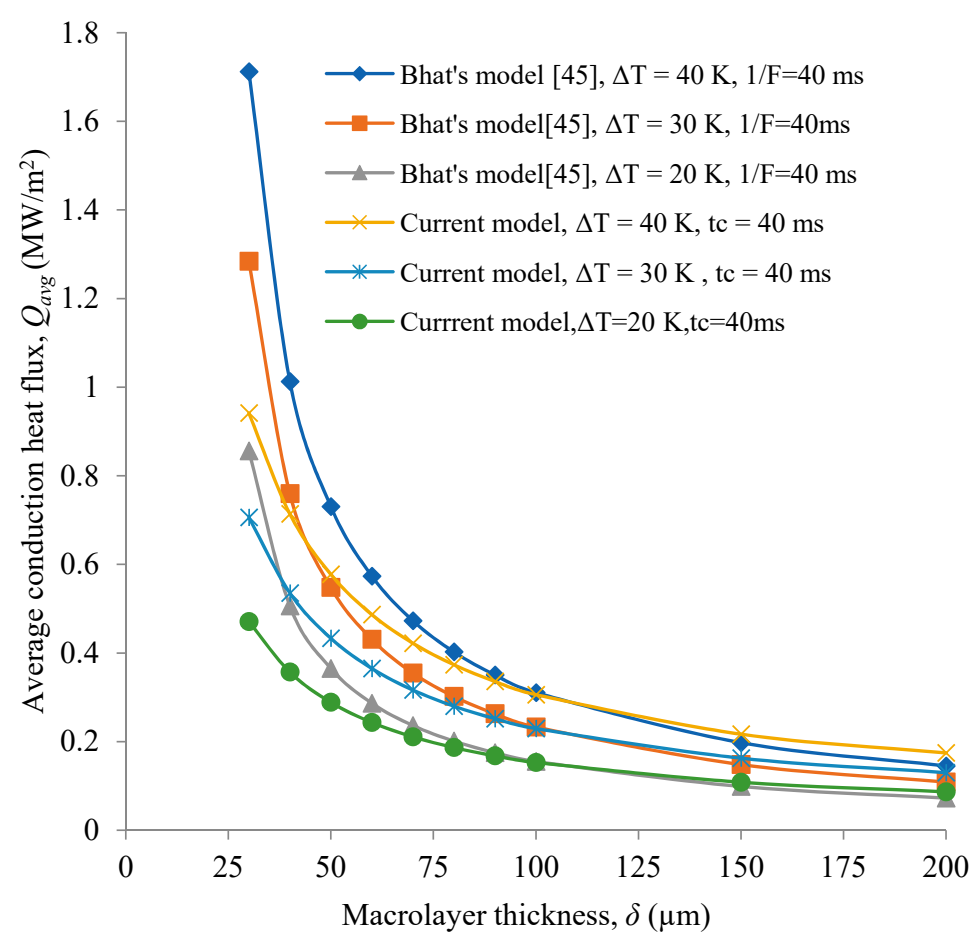

Figure 5. Dependence of average conduction heat fluxes on macrolayer thickness $\left(t_{c}=40 \mathrm{~ms}, 1 / \mathrm{F}=40 \mathrm{~ms}\right)$.

The comparative results of average heat fluxes with macrolayer for the current model and Bhat's model [45] are presented in Figure 6. The data are obtained for wall superheats of $20 \mathrm{~K}, 30 \mathrm{~K}$, and $40 \mathrm{~K}$, and a total cycle time of $40 \mathrm{~ms}$ is chosen for analyzing the influence of the macrolayer. It is observed that average heat flux obtained using the current model and Bhat's model [39] declined with increased macrolayer thickness from $30 \mu \mathrm{m}$ to $200 \mu \mathrm{m}$. In all cases, it is observed that increased macrolayer thickness contributed negatively to the average conduction heat flux, as evident from the curves. The current model predicts an average heat flux of $0.9528 \mathrm{MW} / \mathrm{m}^{2}$ at $\Delta T$ value of $40 \mathrm{~K}$ with a macrolayer thickness of $25 \mu \mathrm{m}$. The average conduction heat flux predicted by the current model declined from $0.7068 \mathrm{MW} / \mathrm{m}^{2}$ to $0.1349 \mathrm{MW} / \mathrm{m}^{2}$ with increased macrolayer thickness from $30 \mu \mathrm{m}$ to $200 \mu \mathrm{m}$. Bhat's model predicted a maximum conduction heat flux of $1.3501 \mathrm{MW} / \mathrm{m}^{2}$ at a $\delta$ of $30 \mu \mathrm{m}$ under the constant condition of wall superheat $(\Delta T=40 \mathrm{~K})$ with a total cycle period of $20 \mathrm{~ms}$. The deviations between the average fluxes predicted by both models are less pronounced with increased macrolayer thickness. It is observed that the $Q_{a v g}$ obtained using the proposed model and Bhat's existing model is nearly the same at a macrolayer thickness range of $75 \mu \mathrm{m}$ to $100 \mu \mathrm{m}$. 


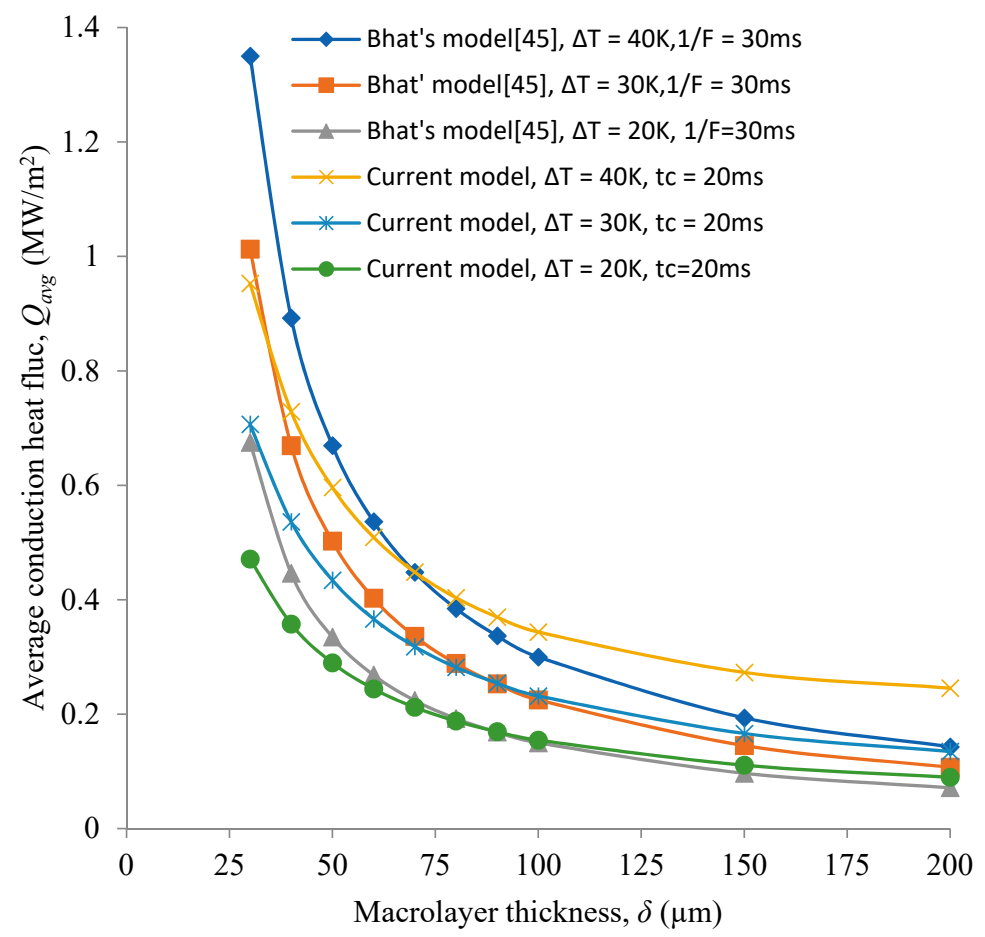

Figure 6. Prediction of average heat flux on macrolayer thickness $\left(t_{c}=20 \mathrm{~ms}, 1 / \mathrm{F}=30 \mathrm{~ms}\right)$.

\subsection{Model Validation}

The variation of heat fluxes on superheat using predicted and experimental results is presented in Figure 7. The predicted results of the proposed current model are compared with Bhat's model [45] and also with the experimental values of the heat fluxes obtained [3]. The data for the predicted result are obtained at a $\delta$ value of $50 \mu \mathrm{m}$. In all the cases, it is observed that conduction or flux robustly depends on $\Delta T$ and increases almost linearly with increased temperature. The experimental wall heat flux increases from $0.6259 \mathrm{MW} / \mathrm{m}^{2}$ to $1.6567 \mathrm{MW} / \mathrm{m}^{2}$ with increased wall superheat from $10 \mathrm{~K}$ to $60 \mathrm{~K}$. Bhat's model predicts a highest flux of $1.3601 \mathrm{MW} / \mathrm{m}^{2}$ at a $\Delta T$ equal to $50 \mathrm{~K}$, corresponding to a $\delta$ value of $50 \mu \mathrm{m}$. The highest flux of $1.3601 \mathrm{MW} / \mathrm{m}^{2}$ is achieved for the proposed model at a maximum heat flux of $50 \mathrm{~K}$ and decreased to $0.1603 \mathrm{MW} / \mathrm{m}^{2}$ with decreased wall heat flux of $10 \mathrm{~K}$ under the constant condition of macrolayer thickness. It is also noticed that predicted values of conduction heat fluxes using the proposed model are higher than that of Bhat's model at any value of wall superheat.

The comparative prediction of conduction or wall superheat with the macrolayer is shown in Figure 8. The predicted results of Bhat's model and the current model are obtained at $40 \mathrm{~K}$. In all the cases, it is observed that the energy exchange rate decreases with increased thickness of the macrolayer. The experimental flux of $1.6645 \mathrm{MW} / \mathrm{m}^{2}$ is obtained for a macrolayer thickness of $50 \mu \mathrm{m}$. The current model predicts conduction heat fluxes of $1.2692 \mathrm{MW} / \mathrm{m}^{2}$ and $0.9574 \mathrm{MW} / \mathrm{m}^{2}$ at times of $10 \mathrm{~ms}$ and $15 \mathrm{~ms}$, respectively, under a constant condition of wall superheat of $40 \mathrm{~K}$. On the other hand, Bhat's model predicted a highest flux of $2.1199 \mathrm{MW} / \mathrm{m}^{2}$ at a $\Delta T \sim 40 \mathrm{~K}$. The current model predicts higher heat fluxes as compared with that predicted by Bhat's model for macrolayer thickness ranging from $50 \mu \mathrm{m}$ to $200 \mu \mathrm{m}$. The conduction heat flux predicted by the current model declined from $1.6339 \mathrm{MW} / \mathrm{m}^{2}$ to $0.4036 \mathrm{MW} / \mathrm{m}^{2}$ with increased macrolayer thickness from $30 \mu \mathrm{m}$ to $200 \mu \mathrm{m}$ for $t=10 \mathrm{~ms}$. It is concluded that a thinner macrolayer consistently contributes to a higher rate of heat transfer through macrolayer as compared with that of thicker macrolayer. An $\mathrm{R}^{2}=0.879$ is achieved with reference to Figure 8 for predicted data of current model and the experimental data [3] of conduction heat flux as a function of macrolayer thickness. The standard deviation $(\sigma)$ is estimated to be $\pm 0.174 \mathrm{MW} / \mathrm{m}^{2}$. 
The determined $\mathrm{R}^{2}$ and $\sigma$ values for predicted and experimental values of conduction heat fluxes signify better conformity among the measurements.

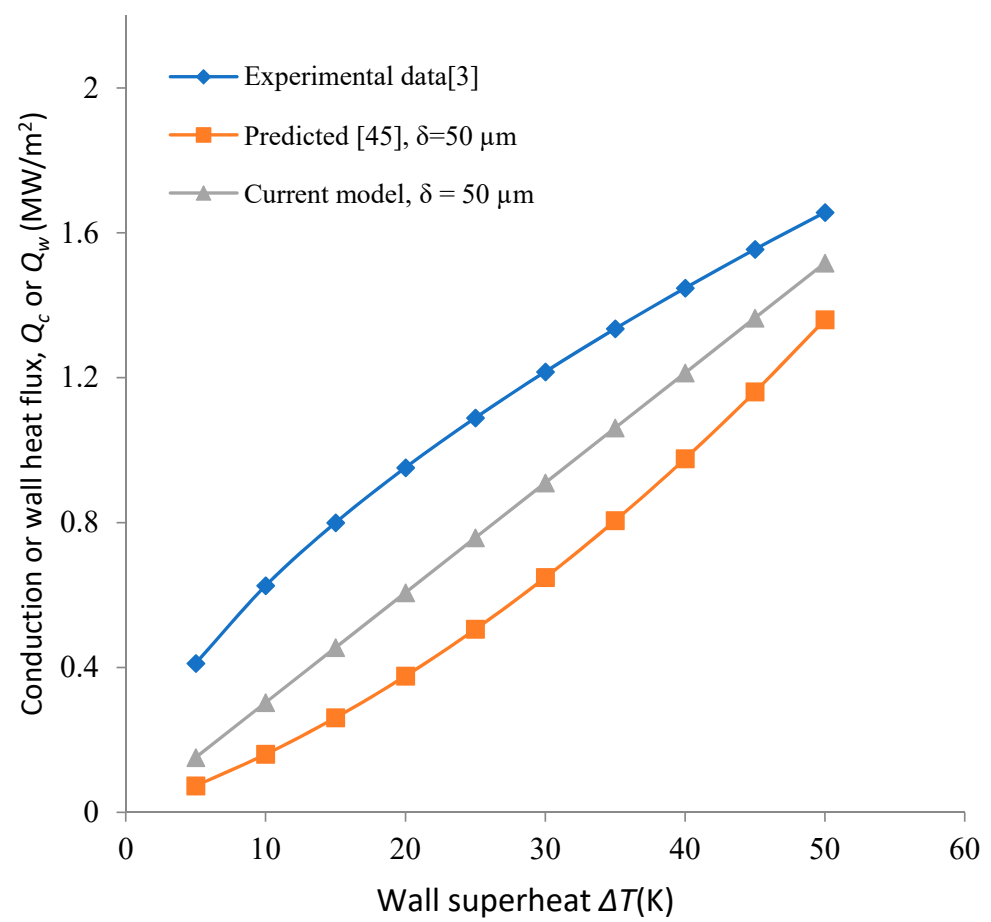

Figure 7. Comparison of predicted heat fluxes with experimental data at a function of wall superheat.

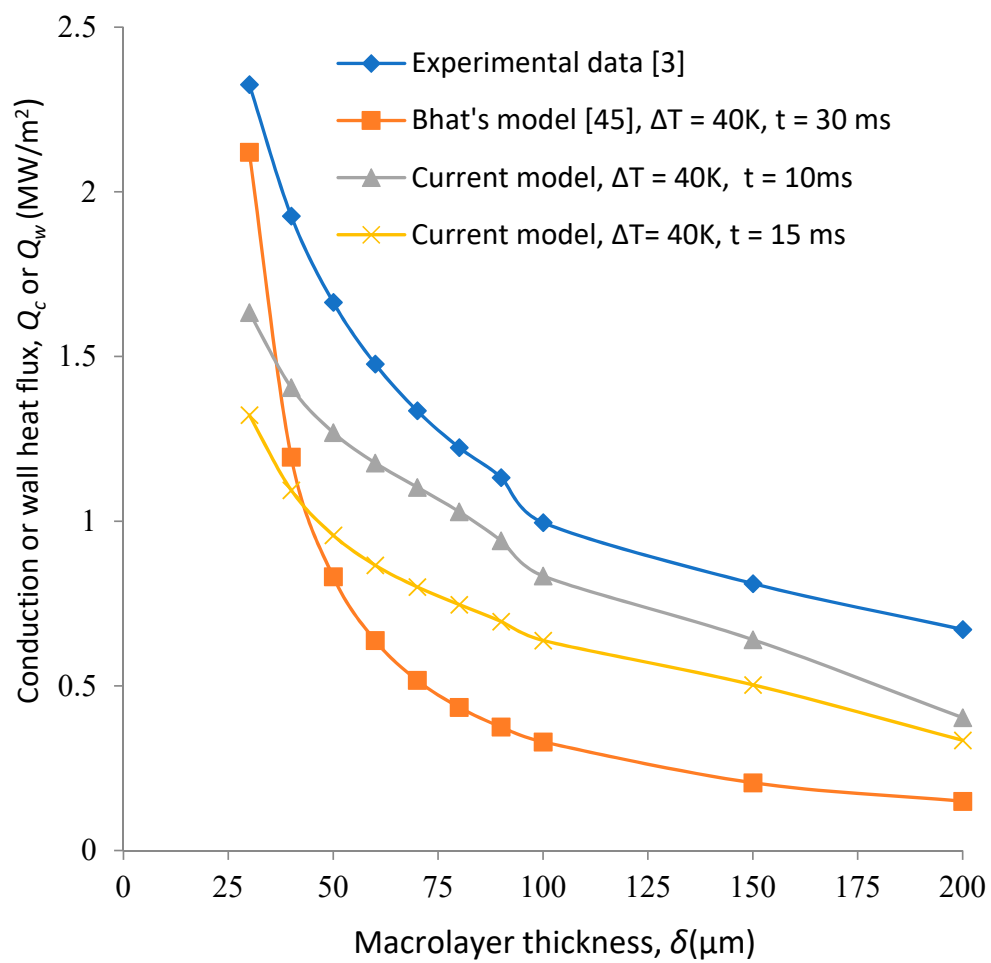

Figure 8. Comparative analysis of predicted heat fluxes with experimental data.

\section{Conclusions}

The mathematical model developed in the current study is capable of estimating the conduction energy transfer through macrolayer in a nucleate regime of pool boiling. 
The current model and Bhat's decreasing macrolayer model predict that conduction heat transfer rate significantly varies with wall superheat, but the effect tends to decline with increased macrolayer thickness. Under the condition of same value of wall superheat, a lean macro-layer exchanges more heat energy comparatively with a thicker macrolayer. The instantaneous values of the heat flux obtained for the proposed model are higher than those obtained using Bhat's decreasing macrolayer model relying on wall $\Delta T$, indicating the significance of the proposed model. The conduction heat fluxes predicted by these models decrease considerably with increased macrolayer thicknesses from $30 \mu \mathrm{m}$ to $200 \mu \mathrm{m}$. The average heat fluxes predicted by both models are nearly the same for a macrolayer thickness of $200 \mu \mathrm{m}$. The average flux increases with increased superheat and a thinner macrolayer contributes significantly to conduction heat transfer. The deviations between average heat fluxes predicted for the existing model and the proposed model decrease with increased macrolayer thickness. The average heat flow rate decreases with increased macrolayer thickness. In addition, the $Q_{\text {avg }}$ obtained using the proposed model and Bhat's model is nearly the same at a macrolayer thickness ranging approximately from $75 \mu \mathrm{m}$ to $100 \mu \mathrm{m}$. The proposed model predicted a heat flux higher than Bhat's model prediction but lower than that of the experimental flux under the condition of variable $\Delta T$.

Author Contributions: Conceptualization, M.D.; Data curation, M.D.; Formal analysis, K.B.A.; Funding acquisition, M.K.A.M.; Investigation, M.D.; Project administration, K.B.A.; Resources, M.K.A.M. and M.H.; Software, A.A.; Supervision, B.A.; Validation, A.A.; Writing-original draft, M.H.; Writing-review \& editing, B.A. All authors have read and agreed to the published version of the manuscript.

Funding: This work was supported by the Deanship of Scientific Research (Grant No. RGP.1/161/42) King Khalid University, Abha KSA.

Conflicts of Interest: The authors declare that they have no conflict of interest.

\section{References}

1. Zuber, N. The Dynamics of Vapor Bubbles in Non uniform Temperature Fields. Int. J. Heat Mass Transf. 1961, 2, 83-98. [CrossRef]

2. Gaertner, R.F. Photographic Study of Nucleate Pool Boiling on Horizontal Surface. ASME J. Heat Transf. 1965, 87, 17-29. [CrossRef]

3. Bhat, A.M.; Prakash, R.; Saini, J.S. On the Mechanism of Macrolayer Formation in the Nucleate Pool Boiling at High Heat Flux. Int. J. Heat Mass Transf. 1983, 26, 735-740. [CrossRef]

4. Gaertner, R.F.; Westwater, J.W. Population of Active Sites in Nucleate Boiling in Nucleate Boiling Heat Transfer. Chem. Eng. Prog. Symp. Se. 1960, 56, 39-48.

5. Katto, Y.; Yokoya, S. Principle Mechanism of Boiling Crisis in Pool Boiling. Int. J. Heat Mass Transf. 1968, 11, 993-1002. [CrossRef]

6. Moissis, R.; Berenson, P.J. On the hydrodynamic transition in nucleate boiling. ASME J. Heat Transf. 1953, 85, $221-229$.

7. Dhir, V.K. Mechanistic Prediction of Nucleate Boiling Heat Transfer-achievable of a Hopeless Task? J. Heat Transf. 2006, 128, 1-12. [CrossRef]

8. Rahman, M.M.; Pollack, J.; McCarthy, M. Increasing Boiling Heat Transfer using Low Conductivity Materials. Nat. Sci. Rep. 2016, 5,1-11. [CrossRef]

9. Dhillon, N.S.; Buongiorno, J.; Varanasi, K.K. Critical Heat Flux Maxima During Boiling Crisis on Textured Surfaces. Nat. Commun. 2015, 6, 1-12. [CrossRef]

10. Rohsenow, W.M. A Method Correlating Heat Transfers Data for Surface Boiling Liquids. Trans. ASME 1952, 74, 876-969.

11. Zuber, N. Nucleate Boiling-The Regions of Isolated Bubbles and Similarity with Natural Convection. Int. J. Heat Mass Transf. 1963, 6, 53-78. [CrossRef]

12. Hoang, N.H.; Song, C.-H.; Chu, I.-C.; Euh, D.-J. A bubble dynamics-based model for wall heat flux portioning during nucleate pool boiling. Int. J. Heat Mass Transf. 2017, 112, 454-464. [CrossRef]

13. Xu, J.J.; Lu, Z.Q. Boiling Heat Transfer and Gas Liquid Two Phase Flow; Nuclear Energy; China Atomic Energy Press: Beijing, China, 2001; pp. 64-68.

14. Carey, V.P. Pool Boiling, Liquid-Vapor Phase-Change Phenomena: An Introduction to the Thermophysics of Vaporization and Condensation Process in Heat Transfer Equipment; CRC Press: Boca Raton, FL, USA, 2008.

15. Rostamzadeh, A.; Jafarpur, K.; Rad, E.G. Numerical Investigation of Pool Boiling in Nanofluid with Lattice Boltzmann Method. J. Theor. Appl. Mech. 2016, 54, 811-825. [CrossRef]

16. Gong, S.; Cheng, P. Numerical Simulation of Pool Boiling Heat Transfer on Smooth Surfaces with Mixed Wettability by Lattice Boltzmann Method. Int. J. Heat Mass Transf. 2015, 80, 206-216. [CrossRef] 
17. Pezo, M.L.; Stevanovic, V.D. Numerical Prediction of Nucleate Pool Boiling Heat Transfer Coefficient under High Heat Fluxes. Therm. Sci. 2016, 20, 113-123. [CrossRef]

18. Gupta, R.R.; Bhambi, S.; Agarwal, V.K. CFD modeling of nucleate bool boiling of nanofluids. Numer. Heat Transf. A 2019, 75, 402-412. [CrossRef]

19. Son, G.; Dhir, V.K. Numerical Simulation of Nucleate Boiling on Horizontal Surfaces at High Heat Fluxes. Int. J. Heat Mass Transf. 2008, 54, 2566-2582. [CrossRef]

20. Deb, S.; Das, M.; Das, D.C.; Pal, S.; Das, A.K. Significance of surface modifications on nucleate pool boiling heat transfer characteristics of refrigerant R-141b. Int. J. Heat Mass Transf. 2021, 170, 120994. [CrossRef]

21. Nunes, J.M.; de Souza, R.R.; Rodrigues, A.R.; Safaei, M.R.; Cardoso, E.M. Influence of coated surface and gap size on boiling heat transfer of deionized water. J. Braz. Soc. Mech. Sci. Eng. 2020, 42, 1-14. [CrossRef]

22. Safaei, M.R.; Tlili, I.; Gholamalizadeh, E.; Abbas, T.; Alkanhal, T.A.; Goodarzi, M.; Dahari, M. Thermal analysis of a binary base fluid in pool boiling system of glucol-water alumina naon-suspension. J. Therm. Anal. Calorim. 2021, 143, 2453-2462. [CrossRef]

23. Stojanovic, A.; Stevanovic, V.; Petrovic, M.; Zivkovic, D. Numerical Study of Heat Transfer During Nucleate Pool Boiling. Adv. Technol. 2016, 5, 73-80. [CrossRef]

24. Lee, G.L.; Law, M.C.; Lee, V.C.-C. Model development and simulation of nucleate pool boiling in openFOAM: Boiling physics in bulk liquid and role of freeboard region. Int. J. Therm. Sci. 2019, 140, 255-279. [CrossRef]

25. He, Y.; Shoji, M.; Maruyama, S. Numerical Study of High Heat Flux Pool Boiling Heat Transfer. Int. J. Heat Mass Transf. 2001, 44, 2357-2373. [CrossRef]

26. Jia, H.W.; Zhang, P.; Fu, X.; Jiang, S.C. A Numerical Investigation of Nucleate Boiling at a Constant Surface Temperature. Appl. Therm. Eng. 2015, 88, 248-257. [CrossRef]

27. Sato, Y.; Niceno, B. A depletable micro-layer model for nucleate boiling. J. Comput. Phys. 2015, 300, 20-52. [CrossRef]

28. Xiaobin, Z.; Wei, X.; Jianye, C.; Yuchen, W.; Tang, K. CFD Simulations and Experimental Verification on Nucleate Pool Boiling of Liquid Nitrogen. Phys. Procedia 2015, 67, 569-575. [CrossRef]

29. Sanna, A.; Hutter, C.; Kenning, D.B.R.; Karayiannis, T.G.; Sefiane, K.; Nelson, R.A. Numerical Investigation of Nucleate Boiling Heat Transfer. Int. J. Heat Mass Transf. 2014, 76, 45-64. [CrossRef]

30. Georgoulas, A.; Andredaki, M.; Marengo, M. An enhance VOF method with heat transfer and phase change to characterize bubble detachment in saturated pool boiling. Energy 2017, 10, 1-35.

31. Chouarfa, F.; Benhamza, M.E.H.; Bendjaballah, M. New Model of Heat Transfer in the Process of Nucleate Boiling in Pool: Prediction and Assessment. J. Eng. Phys Thermophys. 2014, 87, 743-752. [CrossRef]

32. Utaka, Y.; Kashiwabara, Y.; Ozaki, M.; Chen, Z. Heat Transfer Characteristics Based on Microlayer Structure in Nucleate Pool Boiling for Water and Ethanol. Int. J. Heat Mass Transf. 2014, 68, 479-488. [CrossRef]

33. Hameed, M.S.; Khan, A.R.; Mahdi, A. Modeling a General Equation for Pool Boiling Heat Transfer. Adv. Chem. Eng. Sci. 2013, 3, 294-303. [CrossRef]

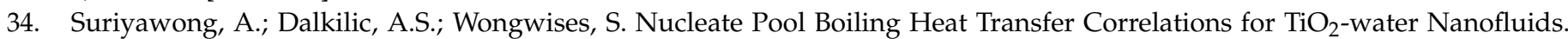
J. ASTM Int. 2012, 9, 1-12. [CrossRef]

35. Chu, H.; Yu, B. A New Comprehensive Model for Nucleate Pool Boiling of Pure Liquid at Low to High Heat Flux Including CHF. Int. J. Heat Mass Transf. 2009, 52, 4203-4210. [CrossRef]

36. Mukherjee, A.; Kandlikar, S.G. Numerical Study of Single Bubbles with Dynamic Contact Angle during Nucleate Pool Boiling. Int. J. Heat Mass Transf. 2007, 50, 127-138. [CrossRef]

37. Kandlikar, S.G. A Theoretical Model to Predict Pool Boiling CHF Incorporating Effects of Contact Angle and Orientation. ASME J. Heat Transf. 2001, 123, 1071-1079. [CrossRef]

38. Maruyama, M.; Shoji, M.; Shimizu, S.A. Numerical Simulation of Transition Boiling, Heat Transfers. In Proceedings of the 2nd JSME-KSME Thermal Engineering Conference, Kitakyushu, Japan, 19-21 October 1992; pp. 345-348.

39. Zhao, Y.H.; Masuoka, T.; Tsuruta, T.M. Theoretical Studies on Transient Pool Boiling Based on Microlayer Model. Trans. JSME B 1997, 63, 218-223. [CrossRef]

40. Haramura, Y.; Katto, Y. A New Hydrodynamic Model of Critical Heat Flux Applicable Widely to Both Pool and Forced Convection Boiling on Submerged Bodies in Saturated Liquid. Int. J. Heat Mass Transf. 1983, 26, 389-399. [CrossRef]

41. Pan, C.; Hwang, J.Y.; Lin, T.L. The Mechanism of Heat Transfer in Transition Boiling. Int. J. Heat Mass Transf. 1989, 32, 1337-1349.

42. Zuber, N. On the stability of boiling heat transfer. Trans. ASME 1985, 80, 711-720.

43. Dhir, V.K.; Liaw, S.P. Framework for Unified Model for Nucleate and Transition Pool Boiling. ASME J. Heat Transf. 1989, 111, 739-746. [CrossRef]

44. Bhat, A.M.; Saini, J.S.; Prakash, R. Role of Macrolayer Evaporation in Pool Boiling at High Heat Flux. Int. J. Heat Mass Transf. 1986, 29, 1953-1961. [CrossRef]

45. Bhat, A.M.; Prakash, R.; Saini, J.S. Heat Transfer in Nucleate Pool Boiling at High Heat Flux. Int. J. Heat Mass Transf. 1983, 26, 833-840. [CrossRef]

46. Prasad, N.R. Investigation on Pool Boiling Heat Transfer in High Heat Flux. Ph.D. Thesis, University of Roorkee, Roorkee, India, 1984.

47. Jairajpuri, A.M.; Saini, J.S. A New Model for Heat Flow Through Macrolayer in Pool Boiling at Heat Flux. Int. J. Heat Mass Transf. 1991, 34, 1579-1591. [CrossRef] 
48. Danish, M.; Mesfer, M.K.A. Analytical Solution of Nucleate Pool Boiling Heat Transfer Model Based on Macrolayer. Heat Mass Transf. 2018, 54, 313-324. [CrossRef]

49. Prasad, N.R.; Saini, J.S.; Prakash, R. The Effect of Heater Wall Thickness on Heat Transfer in Nucleate Pool Boiling at High Heat Flux. Int. J. Heat Mass Transf. 1985, 28, 1367-1375. [CrossRef]

50. Bhat, A.M. Studies on Bubble Dynamics and Heat Transfer in Nucleate Pool Boiling at High Heat Flux. Ph.D. Thesis, University of Roorkee, Roorkee, India, 1982.

51. Zhang, C.; Cheng, P. Mesoscale Simulations of Boiling Curves and Boiling Hysteresis under Constant Wall Temperature and Constant Heat Flux Conditions. Int. J. Heat Mass Transf. 2017, 110, 319-329. [CrossRef]

52. Huger, G.; Tanguy, S.; Sagan, M.; Coiln, C. Direct Numerical Simulation of Nucleate Pool Boiling at Large Microscopic Contact Angle and Moderate Jakob Number. Int. J. Heat Mass Transf. 2017, 113, 662-682.

53. Salehi, H.; Hormozi, F. Numerical Study of Silica-water Based Nanofluid Nucleate Pool Boiling by Two-phase Eulerian Scheme. Heat Mass Transf. 2018, 54, 773-784. [CrossRef]

54. Ma, X.; Cheng, P.; Gong, S.; Quan, X. Mesoscale Simulations of Saturated Pool Boiling Heat Transfer under Microgravity Conditions. Int. J. Heat Mass Transf. 2017, 114, 453-457. [CrossRef]

55. Zhang, L.; Fan, L.; Yu, Z.; Cen, K. An Experimental Investigation of Transient Pool Boiling of Aqueous Nanofluids with Graphene Oxide Nanosheets as Characterized by the Quenching Method. Int. J. Heat Mass Transf. 2014, 73, 410-414. [CrossRef]

56. Kim, J.M.; Kim, J.H.; Park, S.C.; Kim, M.H.; Ahn, H.S. Nucleate Boiling in Graphene Oxide Colloids: Morphological Change and Critical Heat Flux Enhancement. Int. J. Multiph. Flow 2015, 85, 209-222. [CrossRef]

57. Das, S.; Saha, B.; Bhaumik, S. Experimental Study of Nucleate Pool Boiling Heat Transfer of Water by Surface Functionalization with $\mathrm{SiO}_{2}$ Nanostructure. Exp. Therm. Fluid Sci. 2017, 81, 454-465. [CrossRef]

58. Liang, G.; Mudawar, I. Pool Boiling Critical Heat Flux (CHF)—Part 1: Review of Mechanism, Models and Correlations. Int. J. Heat Mass Transf. 2018, 117, 1352-1367. [CrossRef]

59. Kiyomura, I.S.; Mogaji, T.S.; Manetti, L.L.; Cardoso, E.M. A Predictive Model for Confined and Unconfined Nucleate Boiling Heat Transfer Coefficient. Appl. Therm. Eng. 2017, 127, 1274-1284. [CrossRef]

60. Chen, Z.; Wu, F.; Utaka, Y. Numerical Simulation of Thermal Property Effect on Bubble Growth with Microlayer Evaporation during Nucleate Pool Boiling. Int. J. Heat Mass Transf. 2018, 118, 989-996. [CrossRef]

61. Dang, C.; Jio, L.; Peng, Q.; Qian, H.; Zhang, X. Experimental and Analytical Study on Nucleate Pool Boiling Heat Transfer of R134a/R245fa Azeotropic Mixtures. Int. J. Heat Mass Transf. 2018, 119, 508-522. [CrossRef]

62. Mori, S.; Utaka, Y. Critical Heat Flux Enhancement by Surface Modification in a Saturated Pool Boiling-A Review. Int. J. Heat Mass Transf. 2017, 108, 2534-2557. [CrossRef]

63. Li, R.; Huang, Z. A New CHF Model for Enhanced Pool Boiling Heat Transfer on Surfaces with Micro-Scale Roughness. Int. J. Heat Mass Transf. 2017, 108, 1084-1093. [CrossRef] 